\title{
FORMAÇÃO DE PROFESSORES EM LIBRAS: EXPERIÊNCIA POR MEIO DAS REDES SOCIAIS FACEBOOK E WHATSAPP
}

\author{
Mariane Della Coletta Savioli Garzotti de Araujo, Raquel Rosan Christino Gitahy. \\ Universidade do Oeste Paulista - UNOESTE, Mestrado em Educação. Presidente Prudente, SP. E-mail: \\ mariane.aee@gmail.com
}

\section{RESUMO}

O artigo realizado é uma experiência de formação de professores em Libras, realizada em uma fundação municipal do interior paulista, no ano de 2015. A pesquisa objetiva compreender a formação permanente por meio do curso de extensão de profissionais de diferentes áreas e docentes na área de inclusão quanto ao ensino da Língua Brasileira de Sinais a partir das interações nas redes sociais Facebook (web 2.0) e Whatsapp (web 3.0). O seu referencial teórico está embasado em Hessel e Hardagh (2012); Silva e Allegretti (2012), Mantoan (2004), Valente; Moran e Arantes (2011). A metodologia de pesquisa é qualitativa do tipo intervenção - ação. Foram participantes trinta e dois cursistas, sendo que estes estiveram conectados por um grupo de Whatsapp e pertenceram ao grupo fechado do Facebook, ambos intitulados Curso Libras Fateb 2015. Como procedimento de coleta de dados foi utilizada a observação das interações e a prática dos cursistas e docentes, quanto ao uso das redes sociais no processo de ensino e aprendizagem. Após as análises das interações vivenciadas durante o curso, observou-se que os participantes obtiveram uma proximidade e afinidade com a Libras de forma natural, por meio das experiências compartilhadas, desenvolveram autonomia e interesse pelas interações, o que propiciou um aprendizado mais seguro e sistemático da língua.

Palavras-chave: Formação docente, Libras, redes sociais, Facebook e WhatsApp.

\section{FORMATION TRAINING OF TEACHERS IN LIBRAS: EXPERIENCE THROUGH SOCIAL NETWORKS FACEBOOK AND WHATSAPP}

\begin{abstract}
The article made is an experience of teacher training in Libras, held in a municipal foundation of inland of São Paulo, in the year 2015. The research aims to understand the formation through the extension course of professionals from different areas and teachers in the area of inclusion on the teaching of Brazilian Sign Language from the interactions in social networks Facebook (Web 2.0) and Whatsapp (Web 3.0). Your theoretical framework is based in Hessel and Hardagh (2012); Silva and Allegretti (2012), Mantoan (2004), Mighty; Moran and Campbell (2011). The research methodology is qualitative of the kind intervention - action. There were thirty-two teacher students, being that they were connected by a group of Whatsapp and belonged to the closed group in Facebook, both entitled Course Fateb Libras 2015. As data collection procedure was used to observe the interactions and the practice of cursistas and teachers, regarding the use of social networks in the process of teaching and learning. After the analysis of the interactions experienced during the course, it was observed that the participants obtained a closeness and affinity with the Libras in a natural way, by means of shared experiences, developed autonomy and interest by interactions, which provided a learning more safe and systematic language.
\end{abstract}

Keywords: Teacher Training, Libras, social networks, Facebook and WhatsApp. 


\section{INTRODUÇÃO}

O artigo realizado, analisa a importância da formação de docentes, bem como o uso de recursos tecnológicos para esse fim, principalmente, quando se trata da formação para a inclusão de alunos com deficiências, estendendo a todas as etapas e modalidades da educação, desde o ensino infantil até o ensino superior. Compreende-se que o uso das tecnologias na educação, nesse contexto, seja de, de suma relevância (BOZZETTO, 2003).

Sabe-se que, muitos professores da classe comum do ensino regular não possuem informação ou formação para adequar recursos ou mesmo utilizá-los com a finalidade de tornar o conteúdo de ensino acessível ao Estudante Público-Alvo da Educação Especial (EPAEE): crianças com deficiências, transtornos globais do desenvolvimento e altas habilidades ou superdotação. Segundo Werneck (2007), a "falta de formação" é um processo silencioso, lento, progressivo e cumulativo de noções inadequadas sobre temas-tabu como a deficiência.

Afirma Sá (2003) que, há a necessidade de formação dos professores para a utilização adequada e eficaz dessas tecnologias, pois o progresso, sucesso e o direito à educação com condições para o pleno desenvolvimento dos EPAEE, pode ficar comprometido se faltarem esses recursos e soluções necessárias ao seu desenvolvimento e acessibilidade no âmbito escolar.

Novidades relacionadas a inclusão dos EPAEEs, dentre eles os de estudantes com surdez bilateral, severa e profunda, e que necessitam da comunicação dada, por meio da Língua Brasileira de Sinais, a Libras, foram introduzidas pela Política Nacional de Educação Especial na Perspectiva da Educação Inclusiva. Portanto, faz-se necessário que essa língua seja incorporada, veiculada e utilizada no âmbito escolar, com intuito de oferecer estratégias pedagógicas e metodológicas, representando a alternativa mais eficaz no processo de atendimento a esses estudantes (BRASIL, 2007).

Observa-se a necessidade de haver a formação de professores do ensino regular, que se encontram ainda sem conhecimentos para o uso efetivo da Libras, afim de que ofereça bases para a inclusão e para o ensino do estudante surdo. Isso porque, o profissional da educação, de acordo com Manzini e Deliberato (2006), possui um papel importante a desempenhar, principalmente, quanto às estratégias de recursos no ensino do estudante surdo.

Nesse sentido, os professores podem conhecer outras modalidades de comunicação e no caso da inclusão do estudante surdo, conhecer e fazer uso da Libras. Ficou estabelecido, segundo a Lei $n$ ㅇ 10.436/02 e o Decreto no 5626/05, que a Libras é a língua principal das comunidades surdas brasileiras.

Nos dias atuais, algumas instituições escolares, já contam com um professor da Educação Especial para atender na SRM, realizando o Atendimento Educacional Especializado (AEE) de estudantes surdos, aplicando recursos de TA e Tecnologias Digitais de Informação e Comunicação (TDIC) com os alunos surdos. Mesmo assim, ainda se faz necessário que o professor da classe comum conheça a Libras em seus diferentes aspectos e saiba trabalhar com esse alunado.

Considerando as premissas anteriores, formou-se com os docentes matriculados no curso intitulado "Curso Libras Fateb 2015", no período de abril a dezembro de 2015, um grupo fechado no Facebook e no WhatsApp, considerados ambientes de formação colaborativos, onde todos os inscritos podiam compartilhar experiências inclusivas com estudantes surdos, enviar informações, discutir sobre conceitos, obras e vídeos sobre Libras, além de realizarem também, por meio de pequenos vídeos a interação prática da língua.

Neste artigo, serão descritos os resultados das interações vivenciadas nessa formação, com foco na possibilidade e velocidade de interação e ensino colaborativo que a Web 2.0 e a Web 3.0 propõem, bem como na importância da aprendizagem da Libras para os professores que atuam nas classes comuns do ensino regular. 


\section{LIBRAS, A LÍNGUA DA COMUNIDADE SURDA BRASILEIRA}

Verifica-se que a língua de sinais pode atuar no processo de emancipação do surdo, afim de que possam fazer parte do compartilhamento de ideias, assim como de transformação da sociedade, entendendo que a valorização da diversidade deve ser o eixo central do convívio social, não só de surdos, mas também dos não surdos e todos que integram a sociedade.

No Brasil, a Libras só passou a receber o status de língua em 24 de abril de 2002 com a sanção da lei no 10.436, regulamentada pelo decreto 5.626 de 05 de dezembro, reconhecendo-a, como meio legal de comunicação e expressão das comunidades surdas brasileiras, prevendo, que o poder público e as concessionárias de serviços públicos devam garantir de forma institucional o apoio e o uso, a difusão da Libras como meio de comunicação com as pessoas surdas.

Dar ao surdo à possibilidade de comunicar-se e expressar-se na língua que lhe é própria, o que facilita sua inclusão em todos os meios, portanto, o aprendizado da língua de sinais é a melhor maneira para estabelecer uma comunicação entre surdos e surdos e mediar a conversa entre surdos e ouvintes.

Assim, o uso adequado da Libras, vai além da sua existência no universo escolar, é necessário que o professor saiba utilizá-la, e seu uso correto poderá colaborar com o estudante surdo, garantindo as necessidades educacionais específicas, fornecendo autonomia e atendendo as condições de acessibilidade.

\section{DESENVOLVIMENTO DA FORMAÇÃO PERMANENTE DE PROFESSORES PARA O USO DA LIBRAS}

Necessário haver a formação dos profissionais da área educacional, para a inclusão de estudantes surdos, pois a formação para a aprendizagem e uso da Libras, objetiva que os estudantes surdos possam se comunicar e fazer uso de outros recursos, afim de ampliar o acesso à educação, de forma igualitária.

A formação de professores, de diferentes perfis, formando-os para o uso da Libras, tornase um grande desafio, pois, deve acontecer com intensidade, respeitando e valorizando os educadores e também o potencial e necessidade do estudante surdo, assumindo a heterogeneidade técnica além de romper com a homogeneidade na formação.

Dessa forma, vislumbrou-se, a necessidade de propiciar aos professores do ensino regular, a formação, por meio das Redes Sociais, permitindo um acesso à informação, dentro do seu contexto e tempo delimitados.

O acesso à informação faz parte, hoje, das novas formas de construção do saber e assim afirmam Valente e Moran (2011),

No entanto, a interação com as pessoas e com os objetos do meio tem sido substituída por "acesso" à informação, usando para isso, por exemplo, os recursos tecnológicos. O simples fato do aluno navegar na web tem sido entendida como uma oportunidade de interagir com a informação e, consequentemente, de construir conhecimento (VALENTE; MORAN, 2011, p. 24-25).

Foi pensada também, a formação permanente de docentes para o ensino da Libras, com o objetivo de que os cursistas pudessem atender a pessoa surda em todo e qualquer setor ou instituição. Em seu decorrer, pôde propiciar a interação desse professor que se tornou estudante, despertando o interesse e o entusiasmo pelo uso das tecnologias de ensino, de forma colaborativa, para o aprendizado da Libras, objetivando melhores práticas educacionais.

O referido curso de extensão de Libras, proposto por uma faculdade do interior de São Paulo, com a carga horária de 180 (cento e oitenta) horas, teve 90 horas presenciais (quinzenais) e 90 horas virtuais, contempladas, por meio das atividades propostas nas Redes Sociais: Facebook e 
WhatsApp. Para aprovação e certificação, houve a necessidade do aproveitamento de no mínimo $70 \%$ de frequência da carga horária total do curso e da participação nas atividades.

No início, foram ofertadas 35 vagas para docentes, dos municípios da região de Birigui e Araçatuba, dentre eles: Clementina, Bilac, Penápolis e Guararapes, tendo permanecido durante toda a formação 32 cursistas profissionais envolvidos com a educação regular. Tais profissionais são professores da educação infantil, professores do ensino fundamental de 10 ao 5 을 ano e de 60 ao 9a ano, professores do ensino médio, assim como coordenadores, estagiários, psicólogo, policiais do Programa Educacional de Resistência às Drogas e à Violência (Proerd) ${ }^{1}$, profissionais e estudantes de cursos de Pedagogia, surdos e demais profissionais que atuam de forma direta e indireta com o ensino regular.

O objetivo dessa formação permanente em Libras, de acordo com o interesse dos profissionais, era formar os professores e demais educadores, para o ensino e a aprendizagem da Libras para comunicação com pessoas com surdez e nesse sentido, conforme ilustra a Figura 1, as interações usando as ferramentas da Web 3.0 permitiram um diálogo efetivo que extrapolou os limites físicos do dia-a-dia, validando a formação permanente.

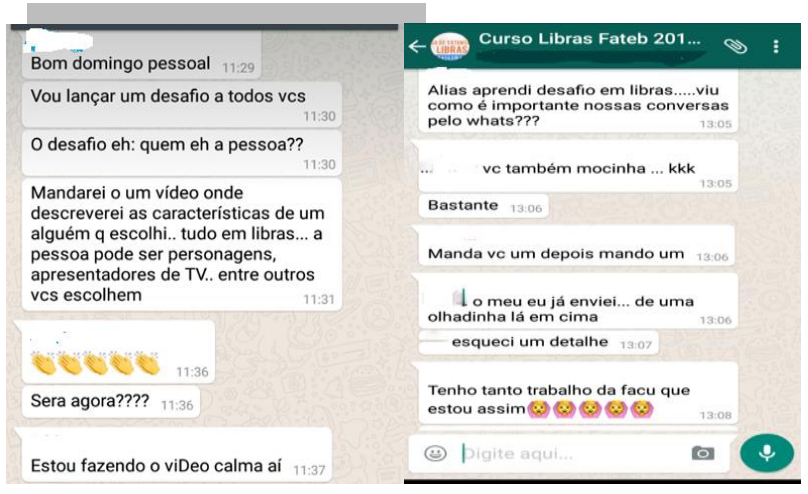

Figura 01. Interações em Libras com desafios para os docentes cursistas colocarem em prática o conhecimento obtido em sala de aula.

Fonte: print screen do aplicativo WhatsApp, Grupo: Curso Libras Fateb 2015.

A formação contou, com a participação e interação nas redes sociais, de estudantes surdos, estudantes de cursos de graduação para formação de professores, dentre eles: Pedagogia e Artes Visuais e outros profissionais surdos, fluentes em Libras, para que pudessem proporcionar uma melhor capacitação e fluência na língua. Os participantes concordaram que as interações realizadas no curso fossem objeto de pesquisa, sendo a mesma submetida e aprovada no comitê de ética, recebendo o CAAE 50758415.7.0000.5515.

As interações tanto no Facebook, quanto pelo WhatsApp, vieram proporcionar maior entrosamento com a Libras pelos cursistas ouvintes, devido as interações com os cursistas e estudantes surdos, podendo ser observadas nas figuras 2 e 3 , a seguir:

\footnotetext{
${ }^{1}$ É um programa de educação preventiva ao uso de drogas, que tem por objetivo evitar que crianças e adolescentes iniciem o seu uso. 


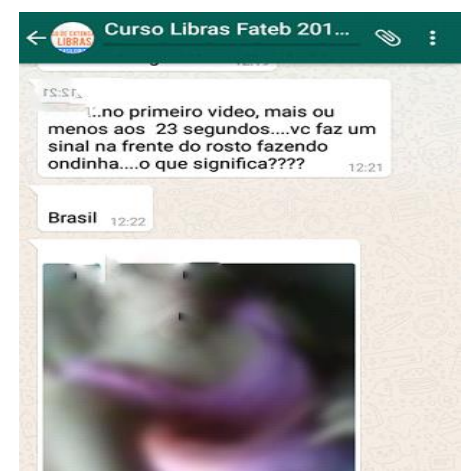

Figura 02. Docente cursista, realizando um questionamento para a Pedagoga surda. Fonte: print screen do aplicativo WhatsApp, Grupo: Curso Libras Fateb 2015.

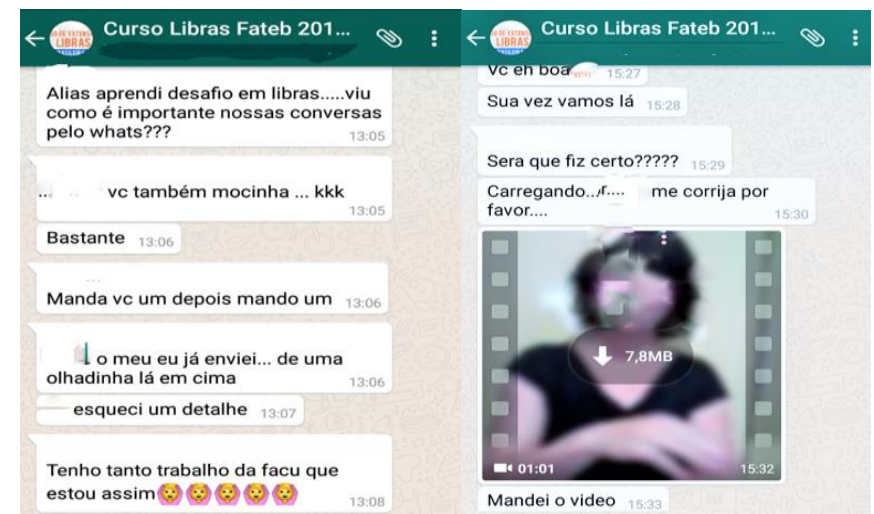

Figura 03. Interações entre docentes cursistas, formador e cursistas surdos Fonte: print screen do aplicativo WhatsApp, Grupo: Curso Libras Fateb 2015.

Dentre as atividades realizadas, conforme a figura 4, foram feitas postagens de vídeo aulas e textos, pela professora. Os professores cursistas, também realizavam postagens de curiosidades, livros, como na figura 5, filmes, reportagens e artigos para serem analisados e discutidos entre os colegas.

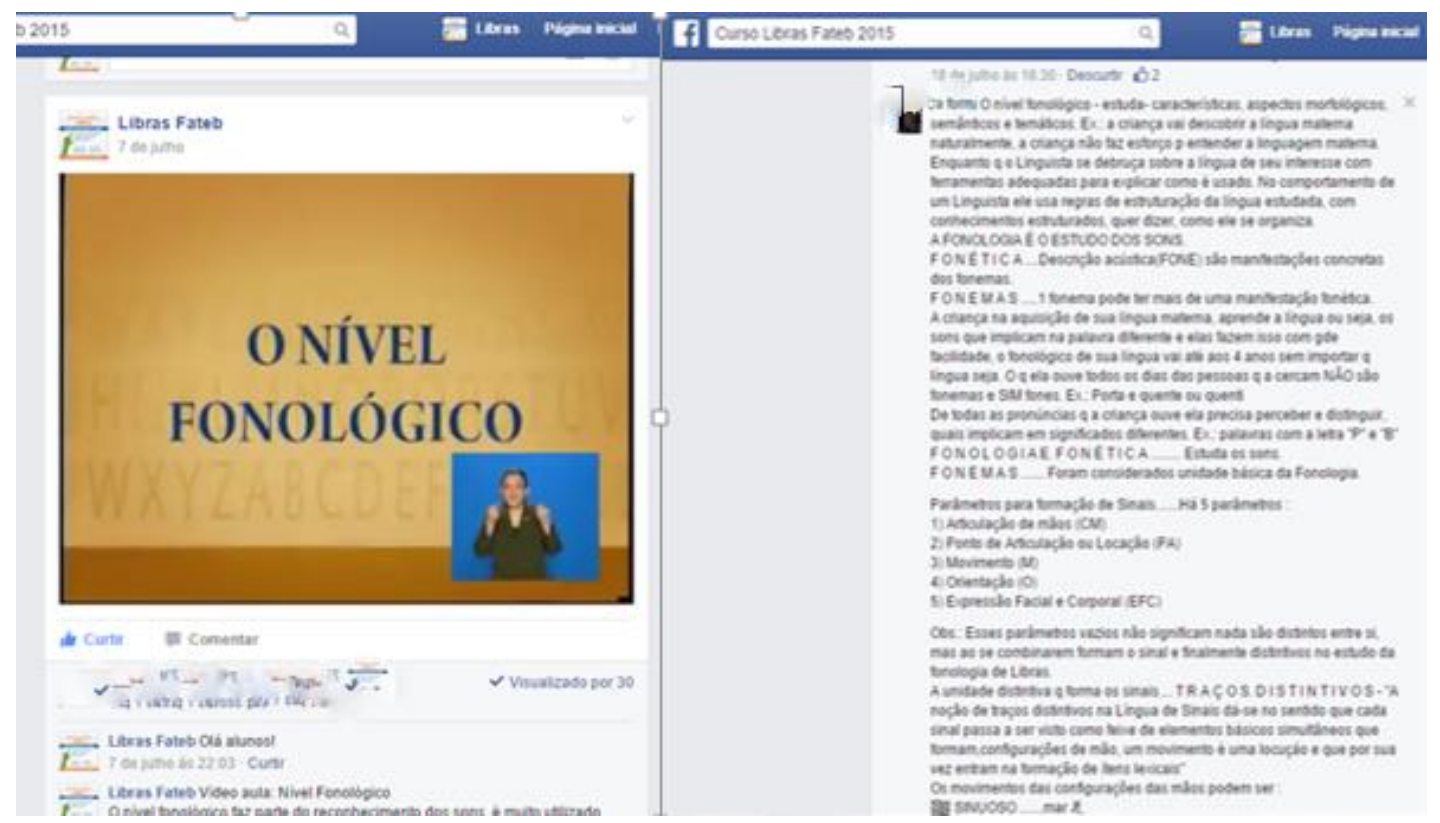

Figura 04. Interação pelo Facebook, Grupo Curso Libras Fateb 2015

Fonte: print screen do Curso Libras Fateb 2015, https://www.facebook.com/groups/LibrasFateb2015/. 


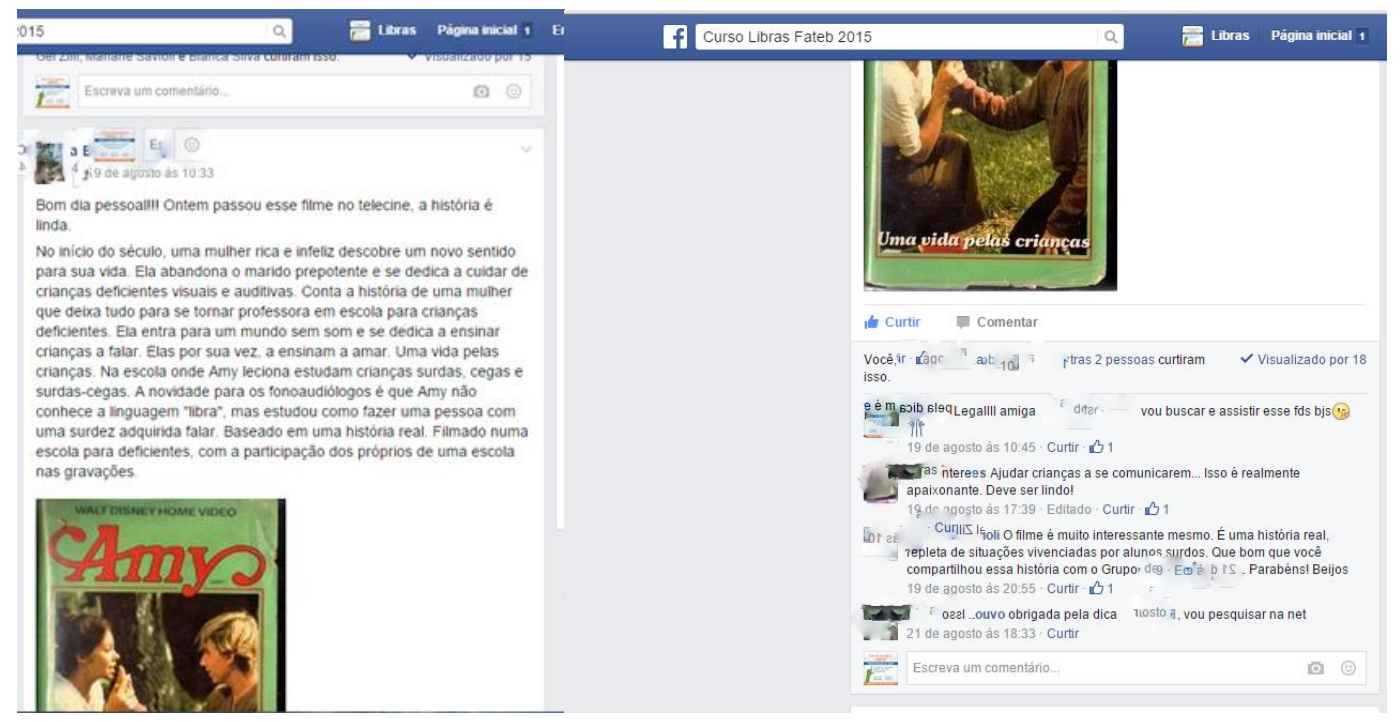

Figura 05. Compartilhamento de Livro com os colegas pelo ambiente Facebook.

Fonte: print screen do Curso Libras Fateb 2015, https://www.facebook.com/groups/LibrasFateb2015/requests/.

Pelo WhatsApp, foram postadas no decorrer do curso, segundo a figura 6, atividades nas quais o professor, surdos e professores cursistas puderam colocar em prática suas habilidades e aprendizado prático de Libras.

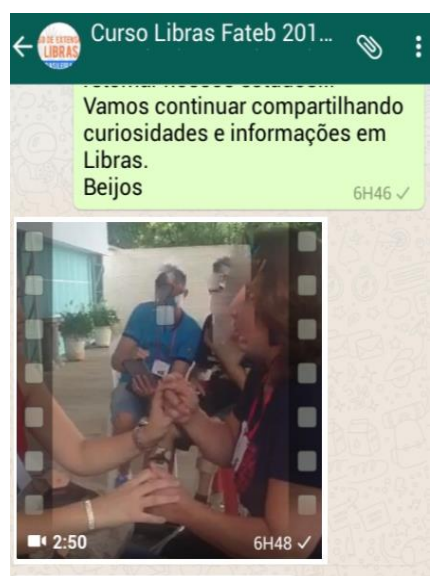

Figura 06. Vídeo, gravado e postado por docente cursista, colocando em prática conhecimentos sobre Libras Tátil em interação com aluna surdocega da Rede Estadual de Ensino. Fonte: print screen do aplicativo WhatsApp, Grupo: Curso Libras Fateb 2015.

Portanto, foram vivenciadas novas formas de construção do saber. Valente e Moran (2011) afirmam que,

a interação com as pessoas e com os objetos do meio tem sido substituída por "acesso" à informação, usando para isso, por exemplo, os recursos tecnológicos. O simples fato do aluno navegar na web tem sido entendida como uma oportunidade de interagir com a informação e, consequentemente, de construir conhecimento. (VALENTE; MORAN, 2011, p. 24-25)

\section{ANÁLISE E DISCUSSÃO}

Para análise foram utilizados como ambiente de formação virtual, as Redes Sociais Facebook (Web 2.0) e o WhatsApp (Web 3.0). A Metodologia da pesquisa é qualitativa do tipo intervenção, quando os pesquisadores são participantes do Curso de Extensão, segundo Minayo (2001). 
O aprendizado aconteceu de forma colaborativa e pela facilidade, frequência e otimização do tempo disponível houve resultados satisfatórios em termos da compreensão da Libras mediante a interação entre os sujeitos. Após as análises das interações vivenciadas durante o curso, observou-se que os participantes obtiveram uma proximidade e afinidade com a Libras de forma natural, por meio das experiências compartilhadas, desenvolveram autonomia e interesse pelas interações, o que propiciou um aprendizado mais seguro e sistemático da língua.

\section{CONSIDERAÇÕES FINAIS}

A experiência compartilhada neste trabalho nos leva a concluir que é possível propor uma formação e informação aos professores e demais profissionais que atuam nas classes comuns do ensino regular, mediante as ferramentas da Web 2.0 e Web 3.0, ou seja, por meio do Facebook e do WhatsApp.

Tem se intensificado o uso das redes sociais, pois cresce a cada dia o número de usuários que querem estar conectados e gostam de compartilhar todo tipo de informações e materiais digitais. Assim há uma expansão das redes para uso social, para uso comercial, para a cultura e para a educação. Na educação, as experiências estão se proliferando e os educadores têm interesse em conhecer aspectos funcionais e vantagens pedagógicas, isso de forma colaborativa, em que podem aplicar os recursos, assim como a comunicação necessária para uma adequada inclusão do indivíduo surdo.

\section{REFERÊNCIAS}

BRASIL. Ministério da Educação e do Desporto. Secretaria da Educação Especial. Política Nacional de Educação na Perspectiva da Educação Inclusiva. Brasília, DF, 2007.

BOZZETTO, S. C.. A Utilização de Recursos Tecnológicos na Educação Infantil. Revista de Pedagogia, número 6, Notas de Pesquisa, 2003.

GOMES, N. L. Diversidade e Currículo. In: BEAUCHAMP, J.; PAGEL, S D.; NASCIMENTO, A. R. Indagações sobre currículo: diversidade e currículo. Ministério da Educação. Secretaria de Educação Básica. Brasília, 2007.

HAYDT, R. C. C.. Curso de Didática Geral. Ática,1997.

HESSEL, A. M.; HARDAGH, C.C.; SILVA, J. E.; ALLEGRETTI, S. M. de M.. Aprendizes na Redes Sociais Virtuais: o potencial da conectividade em dois cenários. Revista CET REGIET, v. 2. 2012.

MANTOAN, M.T.E. O direito de ser diferente na escola. 2004.

MANZINI, J. E.; DELIBERATO, D. Portal de Ajudas Técnicas Para Educação Equipamento e Material Pedagógico Especial Para Educação, Capacitação e Recreação da Pessoa com Deficiência Física. Brasília - DF, MEC/SEESP, 2006.

SÁ, E. D.. Material Pedagógico e Tecnologias Assistivas. Educação Inclusiva no Brasil. Banco Mundial Cnotinfor Potugal, 2003.

THURLER, M. G.. Inovar no interior da escola. Artemed. Porto Alegre, 2001.

VALENTE, J. A.; MORAN, J. M.; ARANTES, V. A. (Org). Educação a Distância: Pontos e Contrapontos. São Paulo. Editora Summus, 2010. 
VALENTE, J. A. (Org.). O computador na sociedade do conhecimento. PROINFO, MEC. Brasília, 2000.

WERNECK, C. Ninguém mais vai ser bonzinho, na sociedade inclusiva. Editora WVA. Rio de Janeiro, 2007.

ZABALA, A.. A Prática Educativa: Como Ensinar. Artemed, 1998. 